\title{
Inclusive education: Open debates and the road ahead
}

\author{
Clementina Acedo $\cdot$ Ferran Ferrer $\cdot$ Jordi Pàmies
}

Published online: 26 November 2009

(C) UNESCO IBE 2009

\begin{abstract}
This special issue is devoted to the outcomes of the 48th International Conference of Education, "Inclusive Education: The Way of the Future" (Geneva, 25-28 November 2008). In addition to presenting the conclusions and recommendations from the conference, this introduction tackles a wide range of questions in the field of inclusive education on which there are still controversy and debate. The issue draws together a selection of articles that analyze these open debates at a deeper level. Special emphasis is placed on several issues: Should inclusive education be a comprehensive approach or follow a policy of piecemeal social engineering? How can educational systems pursue equity and quality simultaneously? What is the role of government, and of decentralization and autonomy? What teaching methods are needed, and what changes in teacher education, development and motivation? Finally, what are the roles of communities, social attitudes, and behaviours?
\end{abstract}

Keywords Inclusive education - Education for All - Social inclusion

This is the second special issue that Prospects is devoting to the topic of Inclusive Education, the theme of the 48th session of the International Conference on Education (ICE)Inclusive Education: The Way of the Future, organized by UNESCO International Bureau of Education (IBE) and held in Geneva from 25 to 28 November 2008.

Inclusive education is one of the greatest challenges facing educational systems throughout the world today, whether we are referring to developing, transition or developed countries. Providing an effective and high-quality education for all children and

C. Acedo $(\bowtie)$

UNESCO IBE, P.O. Box 199, 1211 Geneva 20, Switzerland

e-mail: c.acedo@ibe.unesco.org

F. Ferrer

Barcelona, Spain

e-mail: ferran.ferrer@uab.cat

J. Pàmies

Barcelona, Spain

e-mail: jordi.pamies@uab.cat 
young people remains the main challenge. It entails a two-fold question: How to include the excluded, and at the same time, how to improve the quality and relevance of education in increasingly diverse settings?

Exclusion from education exists in every country, in different forms and to varying degrees. Individuals or groups might be excluded for reasons based on race, socio-economic status, ethnicity, culture, religion, gender, and physical or intellectual capacities. But some students are excluded within the education system itself: they may drop out or they may find themselves in a situation that does not provide them with the most appropriate responses to their basic learning needs and therefore they cannot gain access to the knowledge, skills and competencies they need to integrate successfully into society. Therefore the challenge is to overcome all forms of exclusion, both from education and within education.

It is quite evident that the field of inclusive education is not without uncertainties, disputes and contradictions. In fact, the speeches and discussions at the International Conference of Education (ICE) illustrated a considerable divergence of opinions throughout different countries, governments and international organizations.

Part of the complexity associated with inclusive education stems from its broad definition. At the conference, its meaning differed significantly among participants. This is not surprising; even Ainscow himself refrains from presenting a singular definition, suggesting instead five views of inclusion: in relation to disability and special educational needs; as a response to disciplinary exclusions; in relation to vulnerable groups; as a means of promoting schooling for all, and as Education for All (Ainscow et al. 2006).

For its part, the Guidelines for Inclusion (UNESCO 2005) report uses four key elements to conceptualize inclusive education: it can be seen as a process; it requires the identification and removal of barriers to learning; it aims to have ALL students achieve results in attendance, participation, and quality learning; and it emphasises those groups of learners most at risk of exclusion and marginalization.

These variations in our understanding of inclusive education point to the need to adopt a process-focused approach and to reach a better understanding of the barriers that prevent educational inclusion by examining conditions at the individual level. In this respect it may be useful to consider UNESCO's definition of inclusive education, which is more precise than any available thus far, although a bit long:

Inclusion is seen as a process of addressing and responding to the diversity of needs of all learners through increasing participation in learning, cultures and communities, and reducing exclusion within and from education. It involves changes and modifications in content, approaches, structures and strategies, with a common vision which covers all children of the appropriate age range and a conviction that it is the responsibility of the regular system to educate all children. Inclusion is concerned with providing appropriate responses to the broad spectrum of learning needs in formal and non-formal educational settings. Rather than being a marginal issue on how some learners can be integrated in mainstream education, inclusive education is an approach that looks into how to transform education systems and other learning environments in order to respond to the diversity of learners. It aims towards enabling teachers and learners both to feel comfortable with diversity and to see it as a challenge and enrichment of the learning environment, rather than a problem. (UNESCO 2005, 13-15).

The open debates presented below aim at reflecting both the range of views expressed at the conference and the knowledge derived from educational research on this subject. Based on these sources, we draw attention to the issues in this field on which agreement has not yet been reached. 


\section{Open debates on inclusive education}

What groups are we referring to when we talk about inclusive education?

There appears to be a broad consensus that, in part, inclusion means integrating children with special educational needs in mainstream schools. There is much less agreement about what inclusive education means when we consider groups based on their social class, gender, ethnic group, religious group, mother tongue, or sexual orientation. During the conference and its regional preparatory activities, representatives from different regions each had their own perspectives on this issue. Whereas countries in the Nordic region and Latin America tend to define the concept broadly, in Asia there is still a debate between an "old" and a "new" definition. In Sub-Saharan Africa, the notion is based on specificities in the region, and in Eastern Europe, the Commonwealth of Independent States, and the Arab states, there continues to be reticence about adopting a broader definition (Acedo 2008; Rambla et al. 2008).

Thus a number of questions were left unresolved after the conference, and a question remains: Are there limits to inclusiveness in education depending on the particular groups being considered? How are these limits determined in different countries and regions? Is it plausible to speak genuinely about inclusive education without removing these limits?

Are quality and equity the basic parameters through which inclusive education should be measured?

A considerable amount of recent empirical data shows that both quality and equity can be achieved through inclusive educational systems. Several international surveys-including PISA (Programme for International Student Assessment), TIMSS (Trends in International Mathematics and Science Study) and PIRLS (Progress in International Reading Literacy Study) - have determined that inclusiveness in education does not, in any way, impede or handicap the attainment of high levels of educational quality. Despite this evidence, governments have not yet begun to integrate these two objectives jointly, either in their speeches or in educational policies and practices.

The fact that these two parameters are compatible and necessary as performance indicators does not imply that they are sufficient to evaluate the validity of the process involved in attaining inclusive education. Statistics that measure quality and equity must be complemented with more qualitative indicators that measure transformations in the school system that are made throughout the process.

Is inclusive education a necessary tool in the pursuit of Education for All (EFA)?

According to the EFA 2009 report (UNESCO 2009), significant advances have been made with regards to some of the objectives put forth by the Dakar Framework for Action. In developing countries, primary school attendance has increased steadily. Gender disparities have been reduced in primary and secondary schooling, and more women than men are now enrolled in higher education. Still, inequalities continue to persist, especially when we consider that school admission records do not always accurately reflect results.

The notion that achieving the EFA objectives set up in Dakar is enough to guarantee inclusive education was expressed a number of times at the conference, so much so that EFA and inclusive education were often viewed as interchangeable. It is important to note 
that the educational research published on this issue clearly states otherwise; from this perspective, the concept of inclusive education extends well beyond school coverage for all children and adolescents within a particular area, as it also involves a transformation in learning environments. Inclusive education should not be considered only as the right of children to attend school, but also as their right to good-quality, meaningful learning in both formal and informal settings. This means that the EFA strategy can make important inroads by explicitly addressing inclusive education to improve overall educational quality.

Is inclusive education an end in itself or a process?

Throughout the conference, inclusion was often referred to as an end to be measured in terms of concrete results, rather than as an educational process that involves changes in policy, culture, and practice, as suggested by the UNESCO definition.

Although inclusive education should in part be a quantifiable objective, it must be achieved through a transformative process that changes the fundamental approach of the school by embracing diversity as a positive stimulus that encourages learning. The system as a whole must be planned along inclusive lines.

Does inclusive education constitute the basis of a new paradigm?

While inclusive education seeks to integrate all students within the school system, it goes well beyond the concept of integration-which aims to incorporate students with special educational needs - and maintains that all children must be given equal learning opportunities. Inclusive education may thus be understood as the basis of a new paradigm that bypasses medical approaches and the concept of academic deficiency, and that promotes inclusive environments that embrace diversity. It requires adopting proposals that address the barriers facing those who seek admission to learning and participation (Booth and Ainscow 2002) rather than viewing those barriers as disadvantages. It must therefore support a change in the organizational structure of the school system and in its culture and practices.

Is inclusive education a necessary tool in the realization of human rights?

There does not seem to be a consensus on this issue, mostly due to differences of opinion regarding the definition of human rights themselves and how related policies should be implemented. However, there is agreement that inclusive education must be based on a principle of education as a human right, since it implies that all individuals should be given the opportunity to achieve to their maximum capacities and educational potential regardless of their abilities, thus ascertaining that good quality education is an inalienable human right. In fact, for some authors, the ethical foundation of the inclusive model is based in education as a human right and in the need to actualise human rights (Parrilla 2002).

Is it possible to have a just educational system-one that embodies the principles of justice-without pursuing a model of inclusive education?

Inclusive education is not only a good in its own right-insofar as it promotes a dynamic and comprehensive view of existing diversities in our complex societies-but also 
constitutes an essential strategy for defending the inalienable rights of individuals and groups, especially the most disadvantaged, by promoting their empowerment and the recognition of their attributes. The promotion and defence of inclusive education inherently results in the endorsement of social justice.

Already, some groups and individuals believe that inclusive societies can only be achieved through fair educational practices. Agreement on this issue among all nations would represent a substantial step towards the implementation of an inclusive model, as it would mean rejecting pedagogical practices which, however well intentioned, involve acts and attitudes that exclude certain groups of students.

Does inclusive education have a moral basis, or is it just another educational strategy among the many that currently exist?

It is possible that inclusive education, when defined as a pedagogical strategy, will become dispensable over time. Still, it is an educational model with a moral basis and implications, as it has been created in diverse and inclusive societies, so it requires a higher degree of commitment and consensus among countries. Ultimately, the inclusive approach must be founded on a resolve to build a more democratic and just society.

Should inclusive education be managed using democratic models of school management?

According to the inclusive approach, democratic approaches to management involve sharing responsibility for governing the educational system in such a way that education becomes a collective task. To date, there seems to be little consensus on the best way to manage schools. Although some experts at the conference seemed to be inclined towards a democratic model of management, it is not clear that this issue is inextricably linked to inclusive education. While it may be argued that democratic models of management can exist without being committed to inclusive education, it is difficult to imagine any genuine form of inclusive education existing without a democratic model of school management.

What role should the state and public education authorities play in the move for inclusive education?

Great emphasis is placed on the role of teachers in implementing inclusive education approaches, but often insufficient attention is given to the responsibility of the public authorities who promote these policies. Because the inclusive model of education is complex and requires more time to be implemented effectively, strategies based on political dialogue are indispensable, as is the development of medium- and long-term policies based on a broad consensus and agreements.

On one point there is consensus: in the field of education, the state is seen as responsible for guaranteeing the right to education, providing fair and equitable access to the economic resources devoted to education, and exhibiting a willingness to adapt to the needs of particular groups in the educational system, all of which are important components of inclusive education.

Beyond this point, political practices differ among countries and ideologies. The first issue is whether the state should merely regulate a network of educational establishments 
(including public and private, inclusive and exclusive schools), or whether it should play a more active role in promoting a specific education model.

There also exists a fundamental divergence of opinions as to whether education is a public good that benefits society as a whole-which implies that all citizens should be equally responsible for it - or whether it is a consumption good that generates only individual benefits.

Moreover, the strong presence of the private sector in some education systems means that it is also necessary to determine whether private education can make a genuine contribution to the development of a country's efforts to provide inclusive education and, if so, what the state's role should be in regulating and monitoring that involvement. How and to what extent should the state intervene in the sphere of private education? This issue is still unresolved at the international level.

Should teaching methods be adapted to students' needs?

This principle is at the core of inclusive teaching and learning practices and seems to be broadly accepted, especially in light of the Convention on the Rights of the Child, which stresses the need to make children the focal point of educational policies. It is also generally agreed that whereas assimilation requires that the child be the one to adapt to the school, inclusive education calls upon the school to adapt to the needs of the child, based on the assumption that diversity enriches the teaching and learning processes.

Nevertheless, differences emerge when policies are put into practice. For example, should teaching be personalized to each child in the classroom, or should students be grouped together according to levels of learning achievement? Educational research has identified many drawbacks associated with separating students by levels and thus tends to favour leaving students together while giving them a personalized approach.

Furthermore, because of the complexity involved in working with a diverse group of students, inclusive education requires teachers who are well trained pedagogically and willing to take a stand in support of a model that integrates all students into the school. This type of training should propel teachers to adopt a more holistic approach to their work, hand in hand with other professional educators (such as teachers, educational and cognitive psychologists, counsellors, school doctors, and social workers). It should also involve special education training, so that teachers not specialized in this field are capable, with the help of specialists, of dealing with students who require special needs education.

Of course, training alone is not enough. As one Minister of Education noted at the conference, "inclusive schooling begins with the attitude of the teacher". Attitudes add a complex dimension to inclusive education policies that go beyond amending the system.

Is inclusive education based on a need to establish high expectations for students based on a belief in their capabilities? Or is it adopting a paternalistic attitude in the face of the limited potential attributed to some students?

This issue reflects two very different approaches to inclusive education and to education in general. Both views are an inherent part of discussions that take place on the international stage regarding teaching practices and educational policies. The research-based educational literature clearly demonstrates a positive relationship between students' academic performance and the expectations that their teachers and families create. As a general rule, the higher the expectations, the more confidence students gain in their own potential and the greater their achievements. 
Does inclusive education necessarily imply greater participation by families and community networks in the educative process?

Inclusive education is unlikely to be implemented simply because a government decrees it; that much is agreed upon. While legislation can either foster or hamper the establishment of rules on the basis of a particular educational model, the strength of the approachprecisely because of its underlying ideological character-resides in the capacity for consensus that it can generate among broad sectors of the population, including teachers, public authorities, families, private entities involved in the education sector, and relevant social and economic players (such as employers and trade unions).

Inclusion implies encouraging schools to promote community dialogue and to establish networks of mutual support among families, schools, and other members of the community. The school and social players should share inclusive values in a supportive and stimulating community setting.

In the inclusive system, families must collaborate and share responsibility with teachers by supporting education-related initiatives. The opportunity to work with teachers interested in finding educational solutions based on the students' potential—as opposed to their deficiencies - should encourage this kind of participation.

The success of the inclusive model depends not only on parents' involvement with the schools, but also on their own interaction with their children at home. The open-minded outlook that we wish to propagate among teachers is equally important in the case of families, who transmit a wide range of attitudes within the walls of their home and in their daily interactions with other citizens and institutions in their communities.

Which inclusive education strategies will ensure successful implementation, especially when considering that the concept inherently entails a change in people's mindsets in terms of the kind of society they live in?

Education presupposes a social and civic commitment; therefore the model of education that a society chooses must be in harmony with its desired standards. An inclusive school only makes sense in the context of a society that also aims to be inclusive. While a commitment to inclusion can affect all aspects of the education system-and implies a change in school structures, cultures and practices-school-related issues cannot be separated from political strategies based on a broader model of social equity.

Thus, inclusive education will only be implemented successfully if the concept is agreed upon and accepted by public authorities, social actors and civil society. Coordination among these groups is critical, as is the implementation of inter-sectoral policies in conjunction with more specialized initiatives. This is especially important in the context of local policies, where measures taken on behalf of the most disadvantaged individuals and groups will have the most visible effect.

Should educational inequalities be tackled from the standpoint of the inclusive model?

It is within educational systems and schools themselves that inequalities must be set right, and this can be achieved by giving more support to those with the greatest needs. Some views support differentiated educational strategies that separate children by gender, social class, ethnic origin, performance, etc., claiming that this is the best way to even out results among subgroups of the population. Education and pedagogical literature is in virtually 
unanimous agreement that this practice both worsens academic results and tends to marginalize groups and individuals.

Can educational systems in which students are tracked early (at age 10 or 12) really be considered inclusive?

In these particular education systems, the school is considered responsible for detecting students' limitations as well as their talents. These are then classified as advantages or disadvantages. We know that for a system to be considered inclusive, it must view education differently, and work with students in accordance with their capacities, embracing their diversity, and seeking to overcome obstacles to learning and participation (Ainscow 2005), beginning with a desire for excellence and keeping in mind a broad concept of social equity.

Although comprehensive education is one step towards an inclusive approach, it is not enough. International research has shown that in segregated education systems, a significant proportion of students fail to reach their potential, whereas more inclusive systems tend to offer a better learning experience for all students over time.

How should certain subjects (like religion) be taught in inclusive educational settings?

From the point of view of inclusiveness, it seems evident that the religious education of children and adolescents should be addressed on the basis of diversity, plurality and a mutual understanding of the various beliefs that exist both outside and within each community. Some experts, however, believe that religious education should not be part of school curricula, while others maintain that certain subjects like religion should be addressed through a network of schools, each containing a marked, differentiated, and pluralistic religious character. Teaching practices and educational policies on this subject tend to differ substantially among countries. Even so, there seems to be a consensus on the fact that an inclusive educational approach should acknowledge different religions and be prepared to accept diversity.

What impact can inclusive education have on the process of integrating cultural minorities?

Much attention has recently been given to the education of migrant children by countries hosting immigrant families. There was surprisingly little discussion on this topic at the conference, especially considering that it is very closely tied to the handling of diversity in schools, and that it affects many countries, both developing and developed ones.

Inclusion implies not only recognizing and taking into account the many skills of individuals and groups, but also facilitating the empowerment of minorities and accepting the existence of processes dedicated to creating and preserving multiple, diverse and complex identities. Inclusive education cannot be an excuse to develop policies of cultural assimilation, as it requires going beyond mere integration and involves establishing a positive connotation of diversity.

Are resources the key to the development of inclusive education policies?

The EFA 2009 report indicates that international economic aid for basic education has levelled off or is declining slightly. This form of aid needs to be tripled if the desired objectives are to be attained. 
In a similar way, governments must commit resources if inclusive education is to succeed. Priority must be given to the most critical of elements, for example establishing adequate infrastructures, developing teacher competencies, and implementing suitable pedagogies.

\section{The ICE's conclusions and recommendations on inclusive education}

Although there is still much work to be done in reaching consensus on these debates, the knowledge and experiences shared during the conference helped pave the way for agreement on important issues regarding inclusive education. A series of conclusions and recommendations were developed on the basis of these agreements (UNESCO IBE 2008). To start, inclusive education was established as a fundamental strategy for achieving the EFA goals. Participants also agreed that fostering inclusion implies the active collaboration of all social actors, including the state, private sector, and civil society. Emphasis was placed on formal and informal education opportunities, and the importance of embracing diversity in both of these environments. It was also deemed essential to improve teacher competences, training and working conditions. All countries were called upon to adopt and ratify international conventions related to inclusion and, in particular, the Convention on the Rights of Persons with Disabilities, which was adopted in December 2006. Finally, UNESCO was recognized as playing the lead role in advancing inclusive education by promoting the exchange and dissemination of best practices, providing advice to countries on developing and implementing policies, encouraging South-South and North-SouthSouth cooperation, furthering efforts to increase resources for education at both national and international levels, and making special efforts to assist developing nations affected by conflict as they implement these recommendations.

\section{Introducing the Open File}

In an effort to continue moving the inclusive education agenda forward, the articles in the Open File and in this issue in general seek to address some of the most disputed debates in the field. These articles are inherently linked to the discussions and dialogue that took place during the 48th session of the International Conference of Education.

Inclusive education: comprehensive approach or piecemeal social engineering policy?

Although inclusive education is generally viewed as a holistic concept, debate on how it should be implemented at the policy level is expressed in the two Viewpoints included in this issue. The Viewpoint by Renato Opertti, Jayne Brady and Leana Duncombe presents inclusive education as the core of the EFA agenda. The authors argue that inclusive education involves revisiting core educational concepts through "an integrated and harmonious vision of education, where all components are mutually implicated in their development and impact". This comprehensive approach, the authors believe, will pave the way to real inclusion in education and society.

In contrast, Marc Watkins argues that focusing on transforming the system itself is a "distraction" from the more urgent issues at hand, which he defines as; 1) providing "the best possible education for children with disabilities and increasing their numbers in schools"; and 2) offering "basic education to the $20 \%$ of the world's population who are not 
receiving education or are illiterate". He views calls for institutional change as an inefficient use of limited time and resources. "One is much more likely to find support to remedy problems" he argues, "than to create the ideal school, no matter how strongly the reformer feels he is correct". Watkins instead suggests a "piecemeal social engineering" or targeted approach, with "localized, humane, and realistic" responses that are more effective in improving educational opportunities for excluded children and illiterate adults.

The salient role of equity-and-quality

An important and recurring theme in this issue is the role that the interrelated goals of equity and quality can play in achieving inclusive education. There is a clear consensus among all of this issue's authors that inclusive education is not just about providing access to education for all, but rather about offering meaningful, lifelong learning to all. The concern is that equity and quality are not always acknowledged as interconnected objectives or given the attention that they merit.

For their part, Opertti et al. argue that the EFA goals do not adequately address equity and quality. The authors call for a re-positioning of the agenda in which considerations of equity lead to a more comprehensive understanding of the concept of quality.

In his overview of lessons learned from PISA, Andreas Schleicher emphasizes the important evidence-based conclusions that equity and quality can be achieved simultaneously. Higher quality can also be gained by addressing the key challenge of giving schools greater autonomy while implementing policies to reduce inequalities in performance amongst schools. He presents a number of suggestions based on a recent OECD study that focused on equity and quality-enhancing conditions in five countries (OECD 2007). His suggestions include: limiting early tracking and streaming, ensuring an even social mix in oversubscribed schools through selection methods such as lottery arrangements and financial premiums, and strengthening the links between school and home, especially among migrants and minorities. The model that PISA brings into focus, he believes, is "a flexible school system that offers schools a high level of individual responsibility while simultaneously ensuring their accountability and maintenance of standards, through a system of evaluation and targeted and intensive intervention".

In their analysis of inclusive education and democracy, Juan Eduardo García-Huidobro and Javier Corvalán examine a range of social and political obstacles to achieving equity and quality. Two case studies follow. Susan Peters and Laura Ann Oliver explore how market-based approaches to schooling in the form of high-stakes testing fail to achieve equity and quality in the United States, while Hannu Savolainen investigates how Finland has successfully managed to implement policies that place equity and quality at their core.

In his study on inclusive education in Latin America and the Caribbean, Massimo Amadio illustrates that while the two factors of quality and equity lie at the center of national education policies in this region, the main challenge is putting related principles and policies into practice at the school and classroom level.

The role of government, decentralization and autonomy

There is no doubt that government plays a critical role in the development and implementation of inclusive education policies. But to what extent, and how, should governments be involved? This is a highly contested issue. PISA results, Schleicher explains, suggest that giving schools greater autonomy has a generally positive impact at the system level (although not directly on outcomes). The role of government, he proposes, should be 
to establish frameworks that support the poorer-performing schools that tend to develop in decentralized systems.

In contrast, García-Huidobro and Corvalán focus on the negative effect that marketbased educational systems, decentralization, and autonomy have on schools. They use Chile as an example to show that in decentralized systems, families of higher socioeconomic backgrounds opt for the most prestigious schools, thus marginalizing the less privileged children, who end up in the poorest quality schools. They also caution against short- and medium-term policies that aim to address inequalities, but often merely serve to create more exclusivity. They believe that the underlying problem is a lack of high-level agreement on long-term goals on education. Without this common vision, they claim, even well-intentioned policies can result in exclusion.

For their part, Peters and Oliver emphasize the harmful effect that misguided government-run policies can have on education systems. Policies that apply high-stakes testing accountability, they declare, lead to exclusion and stigmatization since they require that all students meet a pre-determined standard as opposed to recognizing "individual differences, talents, and achievements". The authors propose "decentralized educational systems that provide local autonomy responsive to community contexts", and they offer examples of such models. These include the Accelerated Schools Project (ASP) in the United States, the Escuela Nueva Schools in Latin America, and Finland's comprehensive schools. Savolainen discusses the latter in more detail. In fact, he points to the "Nordictype welfare state", where public authority is responsible for the welfare of all citizens, as the base on which Finland has developed its education system.

Teaching methods, teacher education and development and teacher motivation

Both case studies in this issue clearly demonstrate the important effect that teacher motivation and teacher development and training can have on education. The case is made most strikingly by Savolainen, who notes that in the few studies available on teaching methods, evidence clearly shows that teachers have a much more significant effect on student results than any other factor, such as class size. He attributes much of the success of the Finnish educational system to exceptional teacher training, a rise in the academic status of teachers, and the integration of special education teachers in regular classrooms.

At the other end of the spectrum, Peters and Oliver examine how low teacher morale can hamper student results. They point to evidence showing a "narrowing of the curriculum" and "teachers who are abandoning effective institutional practices to teach to the test" in schools in the United States where results are measured through high-stakes testing. These practices tend to marginalize students who get low scores. The authors also attribute a lack of teacher motivation to "a crisis in the teaching profession" stemming from low salaries, poor working conditions, high teacher drop-out rates, and shortages of qualified teachers in urban schools, where they are most needed.

The role of communities, social attitudes and behaviours

The role of other members of the community (beyond government and teachers) in facilitating inclusive education is another important area of attention. Although the debate continues as to how (if at all) deep-rooted attitudes and behaviours can be changed, there is consensus that inclusive education means embracing diversity not just within school confines, but at every level of society. As Opertti et al. note, negative social attitudes and lack of participation among members of the community create a significant barrier to 
participation and learning. Such is the case in Latin America, where, as Amadio shows, deep-seated negative social attitudes and discriminatory social practices present a major challenge to efforts at inclusive education. Savolainen attributes the success of the Finnish school system in part to a "culture of trust" in which educational authorities and political leaders believe that teachers, together with principals, parents, and their communities, know how to provide the best possible education for their children and youth.

\section{References}

Acedo, C. (2008). Inclusive education: Pushing the boundaries. Prospects, 38(1), 5-13.

Ainscow, M. (2005). Developing inclusive education systems: What are the levers for change? Journal of Educational Change, 6(2), 109-124.

Ainscow, M., et al. (2006). Improving schools, developing inclusion. London: Routledge.

Booth, T., \& Ainscow, M. (2002). The index for inclusion. Bristol, UK: Centre for studies on inclusive education.

OECD. (2007). No more failures: Ten steps to equity in education. Paris: OECD.

Parrilla, M. A. (2002). Acerca del origen y sentido de la educación inclusiva [Concerning the origin and meaning of inclusive education]. Revista de educación, 327, 11-30.

Rambla, X., Ferrer, F., Tarabini, A., \& Verger, A. (2008). Inclusive education and social inequality: An update of the question and some geographical considerations. Prospects, 38(1), 65-76.

UNESCO. (2005). Guidelines for inclusion: Ensuring access to Education for All. Paris: UNESCO.

UNESCO IBE. (2008). Conclusions and recommendations of the 48th session of the International Conference on Education (ICE). http://www.ibe.unesco.org/fileadmin/user_upload/Policy_Dialogue/48th_ ICE/CONFINTED_48-5_Conclusions_english.pdf.

UNESCO. (2009). EFA global monitoring report. Overcoming inequality: Why governance matters. Paris: UNESCO.

\section{Author Biographies}

Clementina Acedo (Venezuela) is director of the UNESCO International Bureau of Education. She holds a $\mathrm{Ph} . \mathrm{D}$. in international and comparative education and master's degrees in philosophy and international development education from Stanford University. She was director of the Institute for International Studies in Education and professor of comparative education and philosophy in the Department of Administrative and Policy Studies at the University of Pittsburgh. Previously she worked for the World Bank. She is the author of several articles and other works on international educational policy, teacher education systems, secondary education reform, and curriculum development in various countries.

Ferran Ferrer (Spain) is professor of comparative education at the Autonomous University of Barcelona (UAB). Coordinator of the UAB Educational Policy and Training Analysis Group and member of the Interdisciplinary Group on Educational Policy and of the European Group for Research on Equity in Education Systems. He has published (as an author and co-author) more than 20 books and 80 articles for specialized journals. He has collaborated with various international organizations, including UNESCO, OEI, CEDEFOP, CESCR and the Council of Europe. He has also taught in several European universities. Former President of the Spanish Comparative Education Society (2002-2006).

Jordi Pàmies (Spain) is associate professor in the Department of Systematic and Social Pedagogy at the Autonomous University of Barcelona (UAB) and a member of the UAB Research Group on Education, Migration and Childhood (EMIGRA). He was a recipient of the Nuffield Foundation's International Fellowship, with a project on children of immigrants in schools (2005-2008). Author and co-author of several articles focusing on migration and education. His dissertation on school performance of Moroccan immigrant children received the Annual Award of the Catalan Government for Youth Studies (2006, Premi Joventut). 